\title{
Kişi-Örgüt ve Kişi-İş Uyumunun Örgütsel Vatandaşlık Davranışı Üzerine Etkisi: Bankacıllk Sektöründe Bir Uygulama ${ }^{1}$
}

\author{
Aybüke CAN² ve Gökhan KERSE ${ }^{3}$
}

\section{$\ddot{\mathrm{O} z}$}

Bu çalışmanın amacı kişi-örgüt ve kişi-iş uyumunun örgütsel vatandaşlık davranışı üzerindeki etkisini araştırmaktır. Bu amaç doğrultusunda araştırma bankacilık sektöründe yapılmış ve Karaman il ve ilçe merkezlerindeki 180 banka çalışanından anket tekniği ile veriler elde edilmiştir. Katılımcı çalışanlar basit tesadüfi örnekleme yöntemiyle belirlenmiş ve analizlerde SPSS programı kullanılmıştır. Amacı uygun istatistiksel analizler yapıldıktan sonra kişi-örgüt uyumunun ve kişi-iş uyumunun örgütsel vatandaşlık davranışını pozitif yönde etkilediği görülmüştür. Boyutsal düzeyde ise kişi-örgüt uyumu ve kişi-iş uyumu, vatandaşlığa ilişkin centilmenlik-vicdanlllık-sivil erdem davranışlarını güçlendirmiştir. Örgütsel vatandaşlık davranışından özgecilik-nezaket ise sadece kişi-örgüt uyumu algısının artmasıyla güçlenmiş, kişi-iş uyumu özgecilik-nezaket davranışını etkilememiştir.

Anabtar Kelimeler: Kişi-örgüt uyumu, Kişi-iş uyumu, Örgütsel vatandaşlık davranışı

The Effect of Person-Organization Fit and Person-Job Fit on Organizational Citizenship Behavior: A Study in Banking Sector

\section{Abstract}

The aim of this study is to investigate the effect of person-organization fit and person-job fit on organizational citizenship behavior. For this purpose, the study was carried out in the banking sector. Data were obtained from 180 bank employees in Karaman provinces and district centers with survey technique. Participants were identified by simple random sampling. Data were analyzed by using SPSS. After statistical analyses, it was observed that personorganization fit and person-job fit effect positively organizational citizenship behavior. At the dimensional level, person-organization fit and person-job fit were strengthened the sportsmanship-conscientiousness-civil virtue behaviors. The altruism-courtesy behavior of organizational citizenship behavior was strengthened only by the increase of perception of person-organization fit; person-job fit did not affect altruism-courtesy behavior.

Key Words: Person-organzational fit, Person-job fit, Organizational citizenship behavior

\section{Atıf İçin / Please Cite As:}

Can, A. ve Kerse, G. (2020). Kişi-örgüt ve kişi-iş uyumunun örgütsel vatandaşlık davranışı üzerine etkisi: Bankacılık sektöründe bir uygulama. Manas Sosyal Arastırmalar Dergisi, 9(4), 2327-2336.

Geliş Tarihi / Received Date: 26.05.2020

Kabul Tarihi / Accepted Date: 23.08.2020

\footnotetext{
${ }^{1}$ Bu çalışma ilk yazarın 2019 yılında tamamladığı Yüksek Lisans Tez çalışmasından oluşturulmuştur.

2 Doktora Öğrencisi - Anadolu Üniversitesi, Sosyal Bilimler Enstitüsü, aybukecan1@hotmail.com, ORCID: 0000-0003-1482-2825

${ }^{3}$ Doç. Dr. - Karamanoğlu Mehmetbey Üniversitesi, İ̈BF, gokhankerse@hotmail.com, ORCID: 0000-0002-1565-9110
} 


\section{Giriş}

Rekabetin hızla arttığı günümüz piyasasında örgütlerin rakipleriyle mücadele etmesi sektörün en iyilerinden biri olmasına bağlıdır. Bunun için hedeflerini gerçekleştirmesi gereken örgütlerin yüksek performans sergileyecek çalışanlara ihtiyaçları vardır. Örgüt ve yöneticiler ayrıca, çalışanlarından performanslarını yükseltecek ekstra davranışlar da beklemektedir. Ekstra davranışlarda çalışanlar iş tanımlarının dışına çıkarak örgüt yararına davranışlar sergilemektedir. Çalışanların performansları ise iş tanımlarını yerine getirip, günü bitirmesi ile yükselmez. Görev tanımlarının ötesindeki ekstra davranışları sergilemesi de gerekir. Çalışanların ekstra davranışlar sergileyebilmesi için ise bazı örgütsel koşulların var olması gerekmektedir. Bu koşullardan birisi ise çalışanın örgüt ve işiyle uyum göstermesidir. Çalısanlar kendileriyle uyumlu iş ve örgütlerde çalıştıları zaman gönüllü olarak ekstra davranışlarda bulunabileceklerdir. Bu yüzdendir ki yöneticiler artık işe alımlarda örgütün hedef, değer ve amaçlarına uygun kişileri seçmeye dikkat etmekte; bireyler ise iş başvurularında kişilik özellikleri ile örtüşen işleri ve örgütleri tercih etmektedir.

Yukarıdaki açıklamalarda da belirtildiği gibi örgütsel performansın artması ve örgütsel yaşamın devam etmesi için çalışanların örgütsel vatandaşlık davranışında bulunması oldukça önemlidir. Bu önem nedeniyle bu çalışma örgütsel vatandaşlık davranışını ele almış; kişi-örgüt ve kişi-iş uyumu kavramlarının örgütsel vatandaşlık davranışına olan etkisini belirlemeyi amaçlamışır. Kavramlara ilişkin yapılan çalışmalar incelendiğinde kişi-örgüt uyumu ile örgütsel vatandaşlık davranışı arasındaki ilişkiyi ele alan çalışmaların (Polatç1, Özçalık ve Cindiroğlu, 2014; Büyükyllmaz, 2018; Afsar ve Badir, 2016) bulunduğu; ancak,kişi-iş uyumu ile vatandaşlık davranışı arasındaki ilişkiyi ele alan çalışmaların (Farzaneh, Farashi ve Kazami, 2014) oldukça sınırlı olduğu görülmüştür. Vatandaşlık davranışının sergilenmesinde örgüt ile uyum kadar iş ile uyumun da dikkate alınması gerekmektedir. Nitekim yeteneklerle ve beklentilerle uyumlu olan bir işte çalışmak vatandaşlık davranışlarının yaygınlaşmasını sağlayabilmektedir (Farzaneh vd., 2014). Bu nedenle çalışmada kişi-örgüt ve kişi-iş uyumunun birlikte vatandaşlık davranışına ve davranış türlerine olan etkisi incelenmiştir.

\section{Teorik Çerçeve ve Hipotezler}

\section{Kişi-Örgüt Uyumu}

Literatür incelendiğinde kişi-örgüt uyumunun farklı şekillerde tanımlandığı ve bu konuyla ilgili farklı modellerin oluşturulduğu görülmektedir. Örneğin Chatman (1989, s. 339) kişi-örgüt uyumunu bireylerin amaçları, değerleri ve tutumları ile örgütün iklimi, kültürü, değerleri ve amaçları arasında ortaya çıkan uyum şeklinde tanımlamıştır. Kristof (1996) ise kişi-örgüt uyumunu, birey ya da örgütten en az biri diğerinin ihtiyacını karşıladığında, aralarında temel benzer özellikler paylaşıldığında ya da her iki durum gerçekleştiğinde ortaya çıkan uyumluluk şeklinde tanımlamıştır (Kristof, 1996, s. 4-5; Meyerink, 2016, s. 2). Kişi-örgüt uyumu alanında çalışma yapan bir diğer araştırmacı olan Schneider ise kişi-örgüt uyumunu Çekim-Seçim-Yıpranma (Attraction-Selection-Attrition-ASA) modeli kapsamında tanımlamıştır. ASA modeline göre belirli özellikleri olan bireyler, belirli özellikleri olan örgütler tarafindan çekilir ve uyum sağlanamadığında ise ayrılır. Örgütte kalanlar ise özellikleri, davranışları, duygu ve deneyimleri ile örgütle benzerlik gösteren kişilerdir (Schneider, 1987, s. 356). Yukarıdaki araştırmalar ve yapılan tanımlar da dikkate alınarak kişi-örgüt uyumunu genel olarak "bireyin değerleri ile örgütün devamlılı̆̆ını sağlamak için benimsediği değerler arasındaki uyum” şeklinde tanımlamak mümkündür.

Bir örgütte kişi-örgüt uyumu sağlandığı zaman bireyler kendilerini daha rahat hissederek sağlıklı bir psikolojiyle çalışabilecekler ve bunun sonucunda çalışmalarından daha çok verim elde edebileceklerdir. Kişi-örgüt uyumunun en önemli getirisi örgüt ve birey arasında güven ilişkisinin kurulacak olmasıdır. Örgüt ile güven ilişkisinin kurulması bireyin aidiyet duygusunu arttıracak, birey örgütün hedeflerini gerçekleştirmek için daha çok çalışacaktır (Ulutaş, 2011, s. 17). Kişi-örgüt uyumunun sağlandığı örgütlerde bireylerin örgütsel bağlllığ daha çok artacak ve bireyler bunun sonucunda örgütsel vatandaşlık davranış1 sergileyeceklerdir (Polatçı ve Cindiloğlu, 2013, s. 311). Örgütlerde kişi-örgüt uyumu ne kadar fazla olursa örgütte çatışmaların azalması (Kartaltepe Behram ve Dinç, 2015) ve örgütsel yabancılaşmanın ortadan kalkması (Büber, 2019) o kadar olası olacaktır.

\section{Kişi-Örgüt Uyumu ve Örgütsel Vatandaşlık Davranışı Arasındaki İlişki}

Örgütsel vatandaşlık davranışı, biçimsel ödül sistemini dikkate almadan örgütün çalşmalarını verimli olarak yapmasına yardımcı olan gönüllülük esasına dayanan davranıştır (Yıldız ve Akgemci, 2011, s. 73). Örgütsel vatandaşlık davranışının Barnard (1938) tarafindan ast ve üst arasındaki ilişkinin örgütsel etkinliğe 
olan etkisini incelemesiyle ortaya çıktı̆̆1 söylenebilir (akt. Zaragoza, 2018, s. 8). Barnard'a göre örgütsel vatandaşlık davranışı bireylerin işbirliği sistemine katkıda bulunma istekleridir. Katz (1964) ise örgütsel vatandaşlık davranışını görevlerin ötesinde olan, ekstra sorumluluklar almaya gönüllü, yenilikçi ve spontan davranışlar olarak tanımlamıştır (Akt:Qureshi, 2015, s. 22).

Örgütsel vatandaşlık davranışı kavramını literatüre kazandıran ve günümüzdeki anlamıyla kullanılmasını sağlayan ise Organ'dır. Organ (1988) örgütsel vatandaşlık davranışını, formal ödüllendirme sistemi içinde doğrudan veya açık bir şekilde tanımlanmayan isteğe bağlı davranışlar olarak tanımlamıştır (Akt:Zaragoza, 2018, s. 8). Dolayısıyla örgütte ortaya çıkan vatandaşlık davranışı görev tanımının ötesindeki davranışları içermekte, söz konusu davranışların sergilenmesinde zorunluluk olmamakta, çalışan bu davranışlara içinden geldiği yani istediği için yönelmekte ve nihayetinde de örgütsel bir fayda ortaya çıkmaktadır.

Örgütlerin hedeflerini gerçekleştirmeleri, verimliliklerini arttırması ve bunların sonucunda başarıyı elde etmesinde çalışanların performansları oldukça önemlidir ve sergilenen bu performanslara bağlıdır. Bu nedenle yöneticiler örgütün değer, hedef ve yetenekleri ile uyum gösterebilecek çalışanları işe almaya dikkat etmektedir. Böylece çalışanlar ve örgütler karşılıklı olarak ihtiyaçlarını karşlayabilecekler ve örgütler iş ortamında avantaj sağlayabileceklerdir. Ayrıca örgütlerin faaliyetlerini yerine getirebilmesi ve yaşamlarını sürdürülebilmesi için çalışanların gönüllü ve istekli bir şekilde örgütün amaçlarına ve hedeflerine katkıda bulunması da gerekir (Koçak, 2018, s. 1488). Sonuç olarak örgüt ile uyumlu çalş̧anların örgütsel vatandaşlık davranışı sergilemesi beklenmektedir. Bu iki kavramı ele alan çalışmalar literatürde mevcuttur. Nitekim Polatçı, Özçalık ve Cindiroğlu 2014 yılında yaptığı çalışmada kişi-örgüt uyumunun üretkenlik karşıt1 iş davranışını azaltıcı, örgütsel vatandaşlık davranışını ise artırıcı etki yaptığını belirlemiştir. Büyükyılmaz, 2018 yllında yaptığı çalısmada algılanan kişi-örgüt uyumu-örgütsel vatandaşlık davranış1 ilişkisinde iş tatminin aracılık rolü olup olmadığını incelemiş ve kişi-örgüt uyumu sağlandığında çalışanların örgütsel vatandaşlık davranışı sergilediğini tespit etmiştir. Afsar ve Badir'in 2016 yllında yaptığı diğer bir çalışmada ise işe gömülmüşlügün hem kişi-örgüt uyumu hem de algilanan örgütsel destek yoluyla örgütsel vatandaşılk üzerindeki llımlı etkileri ve algılanan örgütsel desteğin kişi-örgüt uyumu ile örgütsel vatandaşlık davranışı arasındaki ilişkiye aracılık etkisi incelenmiştir. Çalışmada örgütsel desteğin kişi-örgüt uyumu ile örgütsel vatandaşlık davranışı arasındaki ilişkiye aracılık ettiği görülmüştür. Bu bulgular doğrultusunda aşağıdaki hipotez geliştirilmiştir.

\section{$H_{1}$ : Banka çalssanlarmmn kişi-örgüt uyumu, onlarm örgütsel vatandaşllk davranışm pozitif yönde etkiler.}

\section{Kişi-İş Uyumu ve Örgütsel Vatandaşlık Davranışı Arasındaki İlişki}

Kişi-iş uyumu, iş talepleri ile bireyin becerileri ya da işin özellikleri ile bireyin arzuları arasındaki sağlanan uyumdur (Earnhardt, 2011, s. 9). Kişi-iş uyumu literatüreEdwards (1991) tarafindan kazandırılmıştır. Edwards (1991) kişi-iş uyumunu, iş gerekleri ve bireyin yetenekleri ya da ihtiyaçları ile bireyin işten elde ettiği arasındaki uyum şeklinde tanımlamıştır (Akt:Earnhardt, 2011, s. 9). Kristof Brown (2000) kişi-iş uyumunu bireyin becerilerinin işin gereklerine cevap vermesi ya da işin bireyin beklentilerini karşılaması durumu şeklinde tanımlarken; Sekiguchi (2003) bir kişinin yetenekleri ile bir işin talepleri arasında veya bir kişinin istekleri ile bir işteki istekler arasında sağlanan uyum şeklinde tanımlamışır (akt. Tomlinson, 2012, s. 47). Kerse (2018, s. 945) ise kavram1, doğru niteliklere ve becerilere sahip doğru kişilerin doğru işlere yerleştirilmesi olarak tanımlamıştır. Nitekim işin özelliklerine uygun çalışanların seçilmesi, örgütte birey ve grupların etkin çalısmasını, çalışmalarından verimli sonuçlar elde etmesini, üretim maliyetlerini azaltıp ekonomik karlılığın artmasını sağlamaktadır. Bunun yanında kişi-iş uyumu düzeyinin yüksek olması örgütlerde motivasyonu, işe devamlllığı, iş tatminini ve işgören bağllliğını arttırmaktadır (Sekiguchi, 2004, s. 184).

Modern insan kaynakları yönetiminde işletmeler doğru iş-doğru çalışan anlayışı ile hareket etmektedir. $\mathrm{Bu}$ anlayışla bireyin sahip oldukları özelliklerle işin gerekliliklerinin uygunluk göstermesine dikkat edilmektedir (Yazıc1, 2018, s. 1). Örgütler bu anlayış ile uyumluluk gösteren bireylerin, örgüt amaç ve hedeflerini gerçekleştirmek için sadece iş tanımında yer alan görevleri değil; gönüllü olarak ekstra davranışlarda bulunmasını da beklemektedir. Dolayısıyla iş ile uyumun olması gönüllü bir davranış olan vatandaşlık davranışlarını da yaygınlaştırmaktadır. Literatürde kişi-iş uyumu ile örgütsel vatandaşlık davranışı arasındaki bu ilişkiyi ele alan çalışma oldukça sınırlıdır. Söz konusu ilişki 2014 yılında Farzaneh, Farashi ve Kazami tarafından yapılan çalışma ile incelenmiştir. Çalışmada kişi-iş uyumu örgütsel vatandaşılı davranışını pozitif olarak etkilemiştir. 
Yukarıdaki açıklama ve çalışma bulgusu da referans alınarak aşağıdaki hipotez geliştirilmiştir.

$\mathrm{H}_{2}$ : Banka çalışanlarmın kişi-is uyumu, onlarn örgütsel vatandaşllk davramışın pozitifyönde etkiler.

\section{Yöntem}

\section{Araştırmanın Amacı ve Örneklemi}

Araştırmanın amacı kişi-örgüt uyumu, kişi-iş uyumu ve örgütsel vatandaşlık davranışı arasındaki ilişkiyi belirlemektir. Elde edilen bulgular bireylerin kişi-örgüt ve kişi-iş uyumu göstermelerinin örgütsel vatandaşlık davranışını nasıl etkilediği ve bu etkinin örgütlere ne şekilde fayda sağlayacağı konusunda katkı sağlayacaktır.

Araştırmanın ana kütlesinin Karaman il ve ilçelerinde hizmet veren banka çalışanları oluşturmaktadır. Karaman ilinde faaliyet gösteren yaklaşık 300 banka çalışanı (kamu/özel sektördeki tüm bankalarda) bulunmaktadır (Türkiye Bankalar Birliği, 2018, s. 300). Bankacilık sektörü için müşterilerine kısa sürede cevap vermek ve kaliteli hizmet sunmak oldukça önemlidir. Müşteri isteklerinin hizmet kalitesinden ödün vermeden kısa zamanda karşılanması ise görev tanımının ötesinde davranışlar sergilemeyi gerektirir. Bu davranışların yaygınlaşmasında banka çalışanlarının örgütü ve işi ile uyumu önem göstermektedir. Bunun için ana kütle olarak bankacıllk sektörü tercih edilmiştir. Ana kütleden seçilecek örneklem büyüklügüne ilişkin gerekli hesaplamalar yapılmış ve \%95 güven düzeyinde 169 çalşsanın ana kütleyi temsil ettiği belirlenmiştir (https://www.surveysystem.com/sscalc.htm).Bu doğrultuda 2019 yll Şubat ve Mart aylarında banka çalışanlarına 230 anket gönderilmiş, bu anketlerden 190 tanesinden geri dönüş alınmıştır. 10 adet ankette veri kayıpları yaşanmış; bu nedenle 180 anket üzerinden analizler gerçekleştirilmiştir.

\section{Araştırmada Kullanılan Ölçekler}

Araştırmada veri toplamak için anket tekniğinden yararlanılmışır. Anketi oluşturmak için gerekli literatür taraması yapılmış ve daha önceki çalışmalarda güvenilirliği ve geçerliliği kanıtlanmış ölçekler seçilerek anket formuna dönüştürülmüştür.

Araştırmada kullanılan anket formu 4 bölüm ve 48 maddeden oluşmaktadır. Anketin ilk bölümü medeni durum, yaş, yöneticilik görevi gibi demografik özellikleri ölçmeye yöneliktir. Anketin diğer bölümlerinde ise sırayla kişi-iş uyumu, kişi-örgüt uyumu ve örgütsel vatandaşlık davranışı ölçekleri yer almaktadır. Bu bölümlerde yer alan 42 madde 5'li Likert Ölçeği (1-Kesinlikle Katılmıyorum 'dan 5Kesinlikle Katıllyorum 'a) ile ölçülmüştür.

Araştırmada kişi-örgüt uyumunu ölçmek için 4 maddeden oluşan Netemeyer ve arkadaşlarının (1997) geliştirdiği ölçek kullanılmıştır. Ölçek Türkiye'de de farklı çalışmalarda (Akbaş, 2011; Kerse, Soyalın ve Karabey, 2016) kullanılmıştır.

Araştırmada kişi-iş uyumu toplam 9 madde ile ölçülmüştür. Ölçek Brkich, Jeffs ve Carless (2002) tarafından geliştirilmiş, Kerse (2018) tarafından Türkçeye uyarlanmıştır.

Araştırmada örgütsel vatandaşlık davranışını ölçmek için özgecilik (1-4), nezaket (5-8 ifadeler), centilmenlik (9-12 ifadeler), vicdanlllk (13-16 ifadeler), sivil erdem (17-20 ifadeler) olarak toplam 5 boyut ve 20 madde kullanılmıştır. Maddeler Podsakoff ve Mackenzie'nin (1989) geliştirdiği ve Niehoff ve Moorman'ın (1993) çalışmasında kullandığı ölçekten alınmıştır. Türkiye'de Kalkan (2013) tarafından da kullanılmıştır.

\section{Araştırmada Kullanılan İstatistiki Yöntemler}

Araştırmada elde edilen veriler SPSS paket programı yardımıyla analiz edilmiştir. Çalışmada açıklayıcı faktör analizi, korelasyon analizi ve regresyon analizi kullanılmıştır. Ayrıca banka çalışanlarının demografik özellikleri açısından kişi-örgüt uyumu, kişi-iş uyumu ve örgütsel vatandaşlık davranışında farklılıkların olup olmadığı da incelenmiştir. Farklılıklara ilişkin analizlerde iki gruplu değişkenlerde bağımsız örneklem t testi; ikiden fazla gruplar için ise tek yönlü varyans (Anova) testi kullanılmıstır (Kerse ve Karabey, 2014: 34).

Araştırmada her bir ölçekte yer alan tüm maddelere güvenilirlik analizi yapılmıştır ve Cronbach Alpha Güvenilirlik Ölçütü’nden yararlanılmıştır. Analizde “düzeltilmiş madde toplam puan korelasyonu” 0,30'un altında olan veya analizden çıkarılmasıyla Cronbach Alpha katsayısında önemli ölçüde değişimler olan maddeler değerlendirme dışı bırakılmıştır. Diğer taraftan Cronbach Alpha katsayı değeri 0,70 olarak referans alınmıştır. 
Kişi-örgüt uyumunun güvenilirlik analizinde her bir maddenin toplam puan korelasyon katsayıs1 0,30'dan yüksektir ancak 4. maddenin çıkarılmasıyla Cronbach Alpha katsayısının 0,941e yükseldiği görülmüsş ve söz konusu madde analiz dışı bırakılmıştır. Cronbach Alpha katsayısının 0,941 olması güvenilirliğinin yüksek olduğunu göstermektedir.

Kişi-iş uyumunun güvenilirlik analizinde 2 ve 8 'inci maddeler toplam puan korelasyon kriterini sağlayamadığı için analizden çıkarılmıştır. Geriye kalan 7 maddelik ölçeğin Cronbach Alpha katsayısı 0,900'dür ve ölçek güvenilirliği yüksektir.

Örgütsel vatandaşlık davranışının bütün maddelerinin düzeltilmiş toplam korelasyon puanı 0,30 'dan yüksektir ve Cronbach Alpha katsayısı 0,895'tir. Bu durum ölçek genelinde güvenilirliğin yüksek olduğu anlamina gelmektedir.

\section{Bulgular}

\section{Ölçeklere İlişkin Faktör Analizleri}

Çalışmada ölçeklerin tamamına açıklayıcı faktör analizi ve faktör analizlerinin koşullarını öğrenebilmek için KMO ve Barlett Küresellik Testi uygulanmıştır. KMO'nun 0,60'dan yüksek olması ve Barlett Küresellik testinin 0,000 olması referans olarak alınmıştır. Bu oranlar bize katılımcların yeterli düzeyde olduğunu ve verilerden anlaml faktörler elde edebileceğimizi gösterecektir (Kerse, 2013, s. 74).

Kişi-örgüt uyumu ölçeğinde 3 maddeye açıklayıcı faktör analizi uygulanmıştır. KMO katsayının 0,759 olması verilerin faktör analizine uygun olduğunu, Bartlett Küresellik testinin 0,000 olması ise verilerden anlamlı faktörler çıkacağını göstermektedir. Kişi-örgüt uyumu ölçeğinden tek faktörlü bir yapı elde edilmiş ve toplam varyans $\% 89,435$ olarak açıklanmıştır.

Kişi-iş uyumu ölçeğinde 7 maddeye açıklayıcı faktör analizi uygulanmıştır. KMO katsayısı 0,895 olması verilerin faktör analizine uygun olduğunu göstermektedir. Küresellik testi ise 0,000 'dır ve verilerden anlamlı faktörler çıkacağını ifade etmektedir. 7 maddelik açıklayıcı faktör analizinde tek faktörlü bir yapı elde edilmiş ve toplam varyans \%63,600 olarak açıklanmıştır.

Örgütsel vatandaşlık davranışı ölçeğinde KMO değerinin 0,960 ve Barlett Küresellik testi değerinin 0,000 çıkması referans alınan ölçütleri sağladığını göstermektedir. Bu durum örneklemin analiz için yeterli olduğunu ve anlamlı faktörler elde edilebileceğini göstermektedir. Çalışmada 17 madde ile analiz yapılmıştır, 6, 9, 13 ve 15 'inci maddelerin faktör yükü 0,40'in altında olduğu için analizden çıkarılmıştır. Analiz sonucunda iki boyut/faktör elde edilmiştir. Birinci boyuta "centilmenlik-vicdanllık-sivil erdem"; ikinci boyuta ise "özgecilik-nezaket" adı verilmiştir. Birinci faktör toplam varyansın \%40,244'ünü; ikinci faktör ise toplam varyansın \%34,722'sini açıklamıştır.

\section{Hipotezlerin Testi}

Kişi-örgüt uyumu, kişi-iş uyumu ve örgütsel vatandaşlık davranışı ve onun boyutlarına korelasyon analizi yapıllmış ve sonuçlar Tablo 1'de gösterilmiştir.

Tablo 1. Kişi-Örgüt Uyumu, Kişi-Is Uyumu ve Örgütsel Vatandaşlı Davranışı Arasındaki İliskkiler

\begin{tabular}{|c|c|c|c|c|c|c|c|}
\hline & Ortalama & $\begin{array}{c}\text { Std. } \\
\text { Sapma }\end{array}$ & $\begin{array}{l}\text { Kişi-Örgüt } \\
\text { Uyumu }\end{array}$ & $\begin{array}{l}\text { Kişi-İş } \\
\text { Uyumu }\end{array}$ & $\begin{array}{c}\text { Centilmenlik - } \\
\text { Vicdanlılık- } \\
\text { Sivil Erdem }\end{array}$ & $\begin{array}{c}\text { Özgecilik- } \\
\text { Nezaket }\end{array}$ & $\begin{array}{c}\text { Örgütsel } \\
\text { Vatandaşlık } \\
\text { Davranışı }\end{array}$ \\
\hline $\begin{array}{l}\text { Kişi-Örgüt } \\
\text { Uyumu }\end{array}$ & 3,519 & 1,036 & 1 & & & & \\
\hline $\begin{array}{l}\text { Kişi-İş } \\
\text { Uyumu }\end{array}$ & 3,479 & ,825 & , $678^{* *}$ & 1 & & & \\
\hline $\begin{array}{l}\text { Sportmenlik- } \\
\text { Vicdanlılık- } \\
\text { Sivil Erdem }\end{array}$ & 3,792 & 1,132 &, $560^{* *}$ &, $499^{* *}$ & 1 & & \\
\hline $\begin{array}{l}\text { Özgecilik- } \\
\text { Nezaket }\end{array}$ & 3,781 & ,994 &, $575^{* *}$ & ,471** &, $806^{* *}$ & 1 & \\
\hline $\begin{array}{l}\text { Örgütsel } \\
\text { Vatandaşlık } \\
\text { Davranışı }\end{array}$ & 3,788 & 1,025 &, $593^{* *}$ &, $513^{* *}$ & ,972** &, $923^{* *}$ & 1 \\
\hline
\end{tabular}

Bulgulara göre kişi-örgüt uyumu ile kişi-iş uyumu arasında pozitif yönlü $(0,678)$ bir ilişskiden söz edilebilir. Bunun yanında kişi-örgüt uyumu ile centilmenlik-vicdanlllık-sivil erdem boyutu arasındaki pozitif yöndeki ilişki $(0,560)$, özgecilik-nezaket boyutu arasındaki ilişkiye göre $(0,575)$ daha düşüktür. Kişi-örgüt 
uyumu ile örgütsel vatandaşlık davranışı arasındaki ilişkiye bir bütün olarak bakıldığında da aralarında pozitif yönlü $(0,593)$ bir ilişki olduğu söylenebilir. Diğer bir ifadeyle kişi-örgüt arasındaki uyumunun artması çalışanların örgüt içerisinde örgütsel vatandaşlık davranışı göstermesini de arttırmaktadır.

Tabloya bakıldığında kişi-iş uyumu ile özgecilik-nezaket $(0,471)$ boyutu ve centilmenlik-vicdanlılıksivil erdem arasında pozitif yönde $(0,499)$ ilişki olduğu görülmektedir. Kişi-iş uyumu ile örgütsel vatandaşlık davranışı arasındaki ilişkiye genel olarak baktığımızda da benzer bir ilişki $(0,513)$ olduğu görülmektedir. Diğer bir ifadeyle kişi-iş arasındaki uyum arttıkça çalışanların örgütsel vatandaşlık davranışı göstermeleri de artmaktadır.

Korelasyon analizi ile değişkenler arasında ilişkinin var olduğu saptandıktan sonra çoklu doğrusal regresyon analizi yapılmıştır. Analizde kişi-iş uyumu ve kişi-örgüt uyumu bağımsız değişken olarak ele alınırken; örgütsel vatandaşlık davranışı bağımlı değişken olarak ele alınmıştır. Bulgular Tablo 2'de verilmiştir.

Tablo 2. Kişi-İs Uyumu ve Kişi-Örgüt Uyumunun Örgütsel Vatandaşlık Davranış Üzerine Etkisi

\begin{tabular}{|c|c|c|c|}
\hline \multirow{2}{*}{$\underbrace{\text { Bağımlı }}_{\text {Bağımsız }}$} & \multicolumn{3}{|c|}{ Örgütsel Vatandaşlık Davranışı } \\
\hline & В & $\mathbf{t}$ & $\mathbf{P}$ \\
\hline Kişi-Örgüt Uyumu & 0,450 & 5,619 & 0,000 \\
\hline Kişi-İ̧̧ Uyumu & 0,254 & 2,526 & 0,012 \\
\hline $\mathbf{R}^{2}$ & 0,374 & & \\
\hline Düzeltilmiş $\mathbf{R}^{2}$ & 0,367 & & \\
\hline $\mathbf{F}$ & 52,978 & & \\
\hline
\end{tabular}

Tablo 2 incelendiğinde kişi-örgüt uyumu ve kişi-iş uyumu, örgütsel vatandaşlık davranışının \%37'sini açıklamaktadır. Öte yandan hem kişi-örgüt uyumunun $(0,450)$ hem de kişi-iş uyumunun $(0,254)$ örgütsel vatandaşlık davranışını pozitif yönde etkilediği görülmektedir. Dolayısıyla H1 ve H2 desteklenmektedir. Ayrıca kişi-örgüt uyumunun $(0,450)$ kişi-iş uyumuna $(0,254)$ kıyasla örgütsel vatandaşlık davranışını açıklama gücünün daha yüksek olduğu anlaşılmaktadır. Buradan hareketle kişi-iş uyumuna nazaran kişiörgüt uyumunun örgütsel vatandaşlık davranışında daha belirleyici olduğu söylenebilir.

Kişi-örgüt uyumu ve kişi-iş uyumunun genel örgütsel vatandaşlık davranışı üzerindeki etkisi belirlendikten sonra örgütsel vatandaşlık davranışının "centilmenlik-vicdanlılık-sivil erdem" boyutuna etkisine bakılmıştır. Elde edilen regresyon analizi bulguları Tablo 3’te verilmiştir.

Tablo 3. Kişi-Örgüt Uyumu ve Kişi-Iss Uyumunun Centilmenlik-Vicdanlllk-Sivil Erdem Üzerine Etkisi

\begin{tabular}{lccc}
\hline & Bağımlı & \multicolumn{2}{c}{ Centilmenlik-Vicdanlılık-Sivil Erdem } \\
\cline { 2 - 4 } Bă̆ımsız & $\boldsymbol{B}$ & $\mathbf{t}$ & $\mathbf{p}$ \\
\hline Kişi-Örgüt Uyumu & & 4,921 & $\mathbf{0 , 0 0 0}$ \\
\hline Kişi-İş Uyumu & 0,447 & $\mathbf{0 , 0 0 8}$ \\
\hline $\mathbf{R}^{2}$ & 0,305 & 2,671 \\
\hline Düzeltilmiş $\mathbf{R}^{2}$ & 0,340 & \\
\hline $\mathbf{F}$ & 0,332 & 45,552 \\
\hline
\end{tabular}

Tablo 3'e bakıldığında kişi-örgüt uyumunun ve kişi-iş uyumunun örgütsel vatandaşlık davranışının boyutu olan centilmenlik-vicdanlılık-sivil erdemi pozitif yönde etkilediği görülmektedir. Tablodaki bulgulardan kişi-örgüt uyumunun boyutu açıklamada $(0,447)$, kişi-iş uyumuna kıyasla $(0,305)$ daha güçlü olduğu ifade edilebilir. Tablodaki bulgular H1'nın ve H2'nın desteklendiğini göstermektedir.

Kişi-örgüt uyumu ve kişi-iş uyumunun örgütsel vatandaşlık davranışının “özgecilik-nezaket” boyutuna etkisine ilişkin regresyon analizi bulguları Tablo4' te yer almaktadır. 
Tablo 4. Kişi-Örgüt Uyumu ve Kişi-İș Uyumunun Ö̊gecilik ve Nez̨aket Üzerine Etkisi

\begin{tabular}{|c|c|c|c|}
\hline \multirow{2}{*}{$\mathrm{C}_{\text {Bağımsız }}^{\text {Bağımlı }}$} & \multicolumn{3}{|c|}{ Özgecilik-Nezaket } \\
\hline & B & $\mathbf{T}$ & $\mathbf{P}$ \\
\hline Kişi-Örgüt Uyumu & 0,454 & 5,703 & 0,000 \\
\hline Kişi-İş Uyumu & 0,180 & 1,814 & 0,071 \\
\hline $\mathbf{R}^{2}$ & 0,343 & & \\
\hline Düzeltilmiş $\mathbf{R}^{2}$ & 0,335 & & \\
\hline F & & 46,164 & \\
\hline
\end{tabular}

Tablo 4'e bakıldığında sadece kişi-örgüt uyumunun özgecilik-nezaket boyutunu pozitif $(0,454)$ yönde etkilediği görülmektedir. Dolayısıyla H1 desteklenmekte; H2 ise desteklenmemektedir.

\section{Tartışma, Sonuç ve Öneriler}

$\mathrm{Bu}$ çalışmada kişi-örgüt ve kişi-iş uyumunun örgütsel vatandaşlık davranışı üzerindeki etkisi incelenmiş ve belirlenmiştir. Bu doğrultuda 180 banka çalışanından veriler elde edilmiş ve aşağıdaki sonuçlara ulaşılmıştır:

Araştırmada kişi-örgüt uyumunun örgütsel vatandaşlık davranışını olumlu yönde ve anlamlı düzeyde etkilediği görülmüştür. Analiz sonuçlarına göre; çalışanların örgüt ile aralarındaki uyum arttıkça örgüt yararına gösterdikleri vatandaşıı davranışı da artmaktadır. Elde edilen bu bulgu Polatçı ve arkadaşlarının (2014), Büyükyılmaz'ın (2018) ve Afsar ve Badir'in (2016) bulgularıla paralellik göstermektedir.

Kişi-iş uyumunun da örgütsel vatandaşlı davranışı üzerindeki etkisi pozitif ve anlamlı düzeydedir. Bu bulgu Farzaneh ve arkadaşlarının (2014) elde ettiği bulgu ile tutarlıdır. Dolayısıyla çalışanların işleri ile uyum sağlamaları örgüt adına gösterecekleri vatandaşlık davranışını arttırır. Kişi-örgüt ve kişi-iş uyumunun vatandaşlık davranışına etkisine ilişkin katsayılar incelendiğinde örgüt ile uyumun iş ile uyuma nazaran vatandaşlık davranışlarını daha güçlü etkilediği gözlenmiştir. Yani kişi-örgüt uyumu örgütsel vatandaşlık davranışını belirlemede kişi-iş uyumuna göre daha etkilidir.

Bulguları örgütsel vatandaşlık davranışının boyutları açısından incelediğimizde hem kişi-örgüt uyumunun hem de kişi-iş uyumunun centilmenlik-vicdanlılık-sivil erdem boyutlarını pozitif yönde etkilediği tespit edilmiştir. Bu doğrultuda kişilerin örgütleri ve işleri ile gösterdikleri uyum arttkça sergileyecekleri centilmenlik-vicdanlılık-sivil erdem davranışları da artacaktır. Ancak kişi-örgüt uyumunun kişi-iş uyumuna göre söz konusu davranışları etkileme gücü daha yüksektir.

Araştırmada kişi-örgüt uyumunun ve kişi-ş̧ uyumunun vatandaşlı̆̆ın özgecilik-nezaket boyutuna etkisi de incelenmiş ve örgüt ile uyum özgecilik-nezaket davranışlarını anlamlı düzeyde etkilerken, iş ile uyum anlamlı düzeyde etkilemiştir.

Araştırmada çalışanların demografik özellikleri ile kişi-örgüt uyumu, kişi-iş uyumu, örgütsel vatandaşlık davranışı ve onun boyutları centilmenlik-vicdanllık-sivil erdem ile özgecilik-nezaket boyutları arasında anlamlı farklılıkların olup olmadığı da incelenmiştir. Bazı değişkenler açısından anlamlı farklılıklar görülürken bazılarında görülmemiştir. Sonuçlara göre cinsiyet, medeni durum ve yaş değişkenlerinde farklilıklar oluşmamıştır.

Yöneticilik değişkeninde; yöneticilik görevi olan çalışanlar, yönetici olmayan çalışanlara göre daha fazla kişi-örgüt uyumu ve kişi-iş uyumu göstermiştir.

Eğitim değişkeninin sonuçlarına göre lisans eğitim düzeyinde çalışanlar, lise eğitim düzeyinde çalsşanlara göre daha fazla kişi-örgüt uyumu göstermiştir. Ön lisans eğitim düzeyindeki çalışanlar ise lise eğitim düzeyindeki çalışanlara göre daha fazla kişi-iş uyumu göstermiştir.

Birim değişkeni açısından ise bireysel pazarlama bölümünde çalışan bireyler operasyon bölümünde çalışan bireylere göre daha fazla kişi-iş uyumu göstermiştir. Ticari pazarlama bölümünde çalışan bireyler ise operasyon bölümünde çalışan bireylere göre daha fazla sportmenlik-vicdanll1ık-sivil erdem davranışı ve daha fazla örgütsel vatandaşlık davranışı sergilemiştir. 


\section{Araştırmanın Kısıtları ve Gelecek Araştırmalar için Öneriler}

Çalışmanın en önemli kısıtllıklarından biri araştırmanın ana kütlesinin Karaman ilindeki banka çalışanlarından oluşmasıdır. Dolayısıyla bu durum tüm bankacılık sektörü için genelleme yapılmasını engellemiştir. Diğer bir kısıtlılık ise Karaman ilinde bankaların yarısından fazlası özel banka olduğu için kamu-özel banka çalışanlarının dağılımının eşit olmamasıdır. Ayrıca sektördeki yoğun çalısma temposu, çalısanların sorulara tereddütle cevap vermesine ve bu durumun cevaplara yansımasına yol açmış olabilir.

Diğer taraftan literatürde kişi-iş uyumu ile örgütsel vatandaşlık davranışı arasındaki ilişkiyi inceleyen çalısmalar yok denilecek kadar azdır. Bu durum çalsşmanın güçlü bir yanını göstermektedir. Gelecekteki çalışmalar kişi-iş uyumunun örgütsel vatandaşlık davranışı üzerinde etkisini farklı sektörler açısından ele alabilir. Ayrıca araştırma modeli de örgüt kültürü, kişilik özellikleri vb. farklı değişkenlerle çalışılarak genişletilebilir.

Çalışmadan yola çıkılarak işletme yöneticilerine, insan kaynakları birim çalışanlarına bazı önerilerde bulunulabilir. İşe alım süreçlerinde yöneticiler, kişi-örgüt uyumu ve kişi-iş uyumu gösterecek çalışanları özenle seçmeli, bu doğrultu da çeşitli testler uygulamalı ve süreci sağlıklı bir şekilde tamamlamalıdır. Mevcut çalışanlara ise kişi-örgüt ve kişi-iş uyumunu arttırmaya yönelik eğitimler verilmeli, ödül sisteminin örgütsel vatandaşlık davranışını artıracak seviyede olmasına dikkat edilmelidir. Bu şekilde çalışanlardan daha etkili ve verimli sonuçlar elde edilebilir.

\section{Etik Beyan}

"Kişi-Örö̈t ve Kiși-Iș Uyumunun Öroütsel Vatandașllk Davranıșı Üzerine Etkisi: Bankacıllk Sektöründe Bir Uygulama" başlıklı çalısmanın yazım sürecinde bilimsel, etik ve alıntı kurallarına uyulmuş; toplanan veriler üzerinde herhangi bir tahrifat yapılmamış ve bu çalışma herhangi başka bir akademik yayın ortamına değerlendirme için gönderilmemiştir.

\section{Kaynakça}

Afsar, B. ve Badir, Y. F. (2016). Person-organization fit, perceived organizational support, and organizational citizenship behavior: The role of job embeddedness. Journal of Human Resources in Hospitality \& Tourism,15(3), 252-278.

Akbaş, T. T. (2010). Örgütsel etike iklim, kişi-örgüt uyumu, örgütsel bağhllk ve örgütsel vatandaşlı davranış ilişlkisi: görgül bir araștırma (Doktora Tezi). Gazi Üniversitesi, Sosyal Bilimler Enstiüsü, Ankara.

Brkich, M., Jeffs, D. ve Carless, S. A. (2002). A global self-report measure of person-job fit. European Journal of Psychological Assessment, 18(1), 43-51.

Büber, F. D. (2019). Birey-örgüt uyumu ile örgütsel yabanclaşma arasındaki iliş̧kide örgütsel politikann düzenleyici rolü (Yüksek Lisans Tezi). Nevşehir Hacı Bektaş Veli Üniversitesi, Sosyal Bilimler Enstitüsü, Nevşehir.

Büyükyllmaz, O. (2018). Relationship between person-organization fit and organizational citizenship behavior: the mediating role of job satisfaction. International Journal of Management and Administration, 2(4), 135-146.

Chatman, J. A. (1989). Matching people and organizations: Selection and socialization in public accounting firms. In Academy of Management Proceedings (pp. 199-203). Briarcliff Manor, NY 10510: Academy of Management.

Earnhardt, M. P. (2011). The correlation between person-job fit, job performance, job satisfaction, and motivational gifts in the military context. Londra, University of Regent.

Edwards, J. R. (1991). Person-job fit: A conceptual integration, literature review, and methodological critique. ABD: John Wiley \& Sons.

Farzaneh, J., Farashah, A. D.ve Kazemi, M. (2014). The impact of person-job fit and person-organization fit on OCB.Personnel Review, 43(5), 672-691.

Kalkan, A. (2013). Algzlanan örgüt kültürünün örgütsel vatandaşlı davranısı üzerindeki etkisi: Kuramsal ve görgül bir araștırma (Doktora Tezi). Selçuk Üniversitesi, Sosyal Bilimler Enstitüsü, Konya.

Kartaltepe Behram, N. ve Dinç, E. (2015). Algılanan kişi-örgüt uyumunun kişilerarası çatışma veişten ayrılma niyeti üzerine etkisi.Aksaray Üniversitesi İktisadi ve İdari Bilimler Fakültesi Dergisi, 7(1), 115-124.

Kerse, G. (2013). Personel güllendirme ile bireyin yaratıcllk algısı arasındaki ilişki: Bankacılık sektöründe bir uygulama (Yüksek Lisans Tezi). Atatürk Üniversitesi, Sosyal Bilimler Enstitüsü, Erzurum.

Kerse, G. (2018). The impact of job crafting on person-job fit: "I am compatible with my work because 1 can make changes in my work". Atatürk Üniversitesi İktisadi ve İdari Bilimler Dergisi, 32(4), 941-958.

Kerse, G. ve Karabey, C. N. (2014). Personel güçlendirme ile bireyin yaratıcılık algısı arasındaki ilişki: Bankacılık sektöründe bir uygulama. Akdeniz Üniversitesi İktisadi ve İdari Bilimler Fakültesi Dergisi, 14(29), 22-41.

Kerse, G., Soyalın, M. ve Karabey, C. N. (2016). Kişi-örgüt uyumu, nötrleştirme ve algılanan yönetici desteğinin sanal kaytarmaya etkisi: Ampirik bir çalışma. Aksaray Üniversitesi İktisadi ve İdari Bilimler Fakültesi Dergisi, 8(4), 100-113.

Koçak, D. (2018). Kişi-örgüt uyumu, zorunlu örgütsel vatandaşlık davranışı ve lider-üye etkileşimi ilişkisi. Journal of Graduate School of Social Sciences, 22(3), 1487-1508. 
Kristof, A. L. (1996). Person-organization fit: An integrative review of conceptualizations, measurement, and implications. Personnel psychology, 49(1), 1-49.

Meyerink, D. J. (2016). The influence of person-organization value congruence on applicants' level of attraction towards an organization (Doktara Tezi). University of Middle Tennessee State, Tennessee.

Netemeyer, R. G., Boles, J. S., McKee, D. O. ve McMurrian, R. (1997). An investigation into the antecedents of organizational citizenship behaviors in a personal selling context. Journal of Marketing, 61(3), 85-98.

Niehoff, B. P. ve Moorman, R. H. (1993). Justice as a mediator of the relationship between methods of monitoring and organizational citizenship behavior. Academy of Management Journal, 36(3), 527-556.

Podsakoff, P. M. ve MacKenzie, S. B. (1989). A second ggeneration measure of organizational citizenship behavior(Working Paper). Indiana University, Bloomington.

Polatçı, S. ve Cindiloğlu, M. (2013). Kişi-örgüt uyumunun örgütsel vatandaşlık davranışına etkisi: Duygusal bağlıllğın arac1lık rolü. Süleyman Demirel Üniversitesi İktisadi ve İdari Bilimler Fakültesi Dergisi, 18(3), 299-318.

Polatçı, S., Özçalık, F. ve Cindiloğlu, M. (2014). Üretkenlik karşıtı iş davranışı ve örgütsel vatandaşlık davranışı üzerinde kişi-örgüt uyumunun etkileri. Niğde Üniversitesi İktisadi ve İdari Bilimler Fakültesi Dergisi, 7(3), 1-12.

Qureshi, H. (2015). A study of organizational citizenship behavior (OCB) and its antecedents in an Indian Police Agency (Doktora Tezi). University of Cincinnati, ABD.

Schneider, B. (1987). $\mathrm{E}=\mathrm{f}(\mathrm{P}, \mathrm{B})$ : The road to a radical approach to person-environment fit. Journal of Vocational Behavior, 31(3), 353-361

Sekiguchi, T. (2004). Person-organization fit and person-job fit in employee selection: A review of the literature. Osaka Keidai Ronshu, 54(6), 179-196.

Tomlinson, J. C. (2012). Romans 12 motivational gifts and nurses: An investigation of job satisfaction, person-job fit, and the clifton strengths finder assessment (Doktora Tezi). University of Regent, Londra.

Türkiye Bankalar Birliği. Türkiye'de bankacılık sistemi seçilmis göstergelerin illere ve bölgelere göre dağılımı. Haziran 2018.

Ulutaş, M. (2011). Birey-örgüt uyumunun iş stresi ve verimlilik üzerine etkisi: Dalaman havalimanı çalışanları üzerine bir alan araştırması. Selcuk Üniversitesi Sosyal Bilimler Meslek Yüksek Okulu Dergisi, 14(1-2), 13-30

Yazıc1, U. (2018). Kişi-iș uyumu ile proaktif kişilik ve proaktif çalısmann akademik personel performansı üzerine etkisi: Bartın Üniversitesi örneği (Yüksek Lisans Tezi). Bartın Üniversitesi, Sosyal Bilimler Enstitüsü, Bartın.

Yıldız, N. ve Akgemci, T. (2011). Örgütsel vatandaşlı.. Aykut Bedük (Ed.), içinde Örgütsel psikolojisi yeni yaklaşımlar güncel konular (ss.29-48), Konya: Atlas Akademi.

Zaragoza, K. (2018). Exploring the quality of the leader-follower relationship and its effect on followers' organizational citizenship behaviors in a public-service organization (Doktora Tezi). Brandman University, Kaliforniya.

\section{EXTENDED ABSTRACT}

In this research, the concepts of person-organization fit, person-job fit and organizational citizenship behavior are discussed. Person-organization fit is the harmony between the goals, objectives and values of organization and the goals, objectives and values of employee (Kristof, 1996). Person-job fit is the harmony between the demands of the job and the skills of the individual or the characteristics of the job and the requests of the individual (Earnhardt, 2011) Organizational citizenship behavior is a discretionary behavior that is not included in the official reward system (Zaragoza, 2018). In other words, organizational citizenship behavior refers to the beneficial behaviors related to the job and the organization, which are not included in the employee's job description, but which the employee voluntarily exhibits.

In the research, firstly, a literature review about the relationships between the variables was made. In the literature, it is seen that there are studies dealing with the relationship between organizational citizenship behavior and person-organization fit. In these studies, it was found that person-organization fit positively affects organizational citizenship behavior. It was determined that there was only one study in the examinations carried out for the determination of the studies dealing with person-job fit and organizational citizenship behavior. In this study, it was observed that person-job fit positively affected organizational citizenship behavior. Considering these findings, the following hypotheses were developed in the research:

H1: Person-organization fit of bank employees positively affects their organizational citizenship behavior.

H2: Person-job fit of bank employees positively affects their organizational citizenship behavior.

The data for the testing of hypotheses were obtained from 180 bank employees working in Karaman provinces and district centers. Questionnaire technique was used to obtain the data and analyzed with SPSS program.

Exploratory factor analysis, correlation and regression analysis were used in the study. Besides, independent sample test and one-way variance (ANOVA) test were performed to explain the differences 
between demographic findings. In addition, reliability analysis was performed for the items in each scale. In the analysis, it was found that the scales are reliable and valid.

In the study, first of all, correlation analysis showing the relationship between person-organization harmony, person-job harmony and organizational citizenship behavior was performed. According to the results of the analysis, there was a positive (0.593) relationship between person-organization fit and organizational citizenship behavior. Similarly, it was determined that there is a positive $(0.513)$ relationship between person-job fit and organizational citizenship behavior.

After the correlation analysis, multiple linear regression analysis was performed in accordance with the purpose of the study. According to the results of the regression analysis, it was found that both person-organization fit $(\beta=0.450$ and $\mathrm{p}=0.000)$ and person-job fit $(\beta=0.254$ and $\mathrm{p}=0.012)$ positively affect organizational citizenship behavior. Therefore, $\mathrm{H} 1$ and $\mathrm{H} 2$ hypotheses are supported.

According to the results of the study, person-organization fit and person-job fit have positive effects on organizational citizenship behavior. The fit between employees' personality traits and organizational traits such as organizational culture and organizational purpose was enabled them to exhibit more organizational citizenship behavior. Similarly, the fit between employees' personality traits and skills, job requirements and expectations from employees was enabled them to voluntarily display extra behavior for the benefit of the organization.

In the study, it was also examined whether the demographic characteristics of the employees reveal differences in person-organization fit, person-job fit and organizational citizenship behavior. According to the results, there were no differences in gender, marital status and age variables.

Person-organization fit and person-job fit of executive employees is higher than non-executive employees' person-organization fit and person-job fit.

According to the results of the education variable, the person-organization fit of the employees at the undergraduate education level is higher than those at the high school education level. Person-job fit of employees at associate's level is higher than those at high school level.

In terms of unit variable, individuals working in the individual marketing department showed more person-job fit than individuals working in the operation department. Individuals working in the commercial marketing department, on the other hand, displayed more organizational citizenship behavior than the individuals working in the operation department.

As in all studies, there are some limitations in our study. The fact that the universe is in Karaman provinces and districts causes it not to be generalized for the entire banking sector. In future studies, the relationship between person-job fit and organizational citizenship behavior can be examined by considering different sectors. In addition, the research model can be expanded by adding different variables such as organizational culture, organizational identification and personality traits. 